Cambridge University Press

978-0-521-02886-8 - A Grammar of Tariana, from Northwest Amazonia

Alexandra Y. Aikhenvald

Frontmatter

More information

A Grammar of Tariana

This is a comprehensive reference grammar of Tariana, an endangered Arawak language from a remote region in the northwest Amazonian jungle. Its speakers traditionally marry someone speaking a different language, and as a result most people are fluent in five or six languages. Because of this rampant multilingualism, Tariana combines a number of features inherited from the protolanguage with properties diffused from neighbouring but unrelated Tucanoan languages. Typologically unusal features of the language include: an array of classifiers independent of genders, complex serial verbs, case marking depending on the topicality of a noun, and double marking of case and number. Tariana has obligatory evidentiality - every sentence contains a special element indicating whether the information was seen, heard, or inferred by the speaker, or whether the speaker acquired it from somebody else. This grammar will be a valuable source-book for linguists and others interested in natural languages. 


\section{CAMBRIDGE GRAMMATICAL DESCRIPTIONS}

\section{Editors: R. M. W. Dixon, Keren Rice}

This series is devoted to the publication of comprehensive descriptive grammars of languages that have not previously been documented, and that have interesting and unusual characteristics which will expand our understanding of human language in all its diversity and challenge the limits of current linguistic theory. Some of these languages are spoken by only a small number of people and can be considered endangered.

Each grammar briefly introduces the society in which the language is spoken, and covers the key areas of phonology, morphology and syntax, together with typological and historical considerations. In each case, a sample text or texts in the language are provided, with full gloss and translation. A glossary of basic vocabulary is also included. The series aims to provide theoretical linguists in the various subdisciplines with reliable data and analysis which will provide a permanent and invaluable set of source materials. 
Cambridge University Press

978-0-521-02886-8 - A Grammar of Tariana, from Northwest Amazonia

Alexandra Y. Aikhenvald

Frontmatter

More information

\title{
A GRAMMAR OF TARIANA, FROM NORTHWEST AMAZONIA
}

\author{
Alexandra Y. Aikhenvald \\ Research Centre for Linguistic Typology \\ La Trobe University, Melbourne
}


Cambridge University Press

978-0-521-02886-8 - A Grammar of Tariana, from Northwest Amazonia

Alexandra Y. Aikhenvald

Frontmatter

More information

\section{CAMBRIDGE UNIVERSITY PRESS}

Cambridge, New York, Melbourne, Madrid, Cape Town, Singapore, São Paulo

Cambridge University Press

The Edinburgh Building, Cambridge CB2 2RU, UK

Published in the United States of America by Cambridge University Press, New York

www.cambridge.org

Information on this title: www.cambridge.org/9780521826648

(C) Alexandra Y. Aikhenvald 2003

This publication is in copyright. Subject to statutory exception and to the provisions of relevant collective licensing agreements, no reproduction of any part may take place without the written permission of Cambridge University Press.

First published 2003

This digitally printed first paperback version 2006

A catalogue record for this publication is available from the British Library

ISBN-13 978-0-521-82664-8 hardback

ISBN-10 0-521-82664-0 hardback

ISBN-13 978-0-521-02886-8 paperback

ISBN-10 0-521-02886-8 paperback 
Cambridge University Press

978-0-521-02886-8 - A Grammar of Tariana, from Northwest Amazonia

Alexandra Y. Aikhenvald

Frontmatter

More information

For my Tariana family 
Cambridge University Press

978-0-521-02886-8 - A Grammar of Tariana, from Northwest Amazonia

Alexandra Y. Aikhenvald

Frontmatter

More information

\section{Contents}

List of tables, schemes and diagrams $\mathrm{xv}$

Preface xvii

Acknowledgements xiv

Organisation and cross-referencing $\mathrm{xxi}$

List of abbreviations xxii

Map xxiv

1.The language and its speakers 1

1.1 Linguistic profile of Tariana 1

1.2 Tariana and the multilingual setting of the Vaupés 6

1.3 Historical information about the Tariana 9

1.4 Social organisation 11

1.5 Ceremonies and beliefs 13

1.6 Naming practices 15

1.7 Nonverbal communication 16

1.8 What we know about the Tariana language 17

1.8.1 Denominations of the language 17

1.8.2 Previous studies of the language 18

1.9 Materials and speakers 18

2. Phonology 25

2.1 Segmental phonology 25

2.1.1 Consonants 25

2.1.2 Vowels 32

2.2 Syllable structure, vowel sequences and the problem of diphthongs 34

2.2.1 Syllable structure 34

2.2.2 Vowel sequences and diphthongs 35

2.3 Stress 37

2.3.1 Primary stress 37

2.3.2 Stress in monomorphemic words 38

2.3.3 Stress in polymorphemic words 38

2.3.4 Secondary stress 39

2.3.5 Vowel reduction 39

2.4. Phonological word 40

2.4.1 Primary stress and prosodic classes of morphemes 40

2.4.2 Nasalisation 42

2.4.3 Aspiration 42

2.4.4 Vowel harmony 44

2.4.5 Word delimiting prosodic parameters in Tariana: a summary 45

2.5 Phonological processes 46

2.5.1 H-metathesis 46 
Cambridge University Press

978-0-521-02886-8 - A Grammar of Tariana, from Northwest Amazonia

Alexandra Y. Aikhenvald

Frontmatter

More information

viii Contents

\subsubsection{Vowel fusions 47}

2.5.3 Phonological processes within roots and within affixes 52

2.6 Prosodic classes of morphemes and their properties 53

2.7 Pause marking 60

2.8 Phonological phrase 63

2.9 Intonation patterns 64

3. Word classes 66

3.1 Open word classes 66

3.1.1 Verbs 66
3.1.2 Nouns 68

3.1.3 Adjectives 72

3.1.4 Word class-changing morphological derivations

3.2 Manner adverbs and time words 77

3.3 Closed classes 80

3.4 Word classes and functional slots: an overview 8

4. Nominal morphology and noun structure 82

5. Noun classes and classifiers 87

5.1 Overview of the multiple classifier system 87

5.1.1 Organisation of the system 87

5.1.2 Noun classes 99

5.1.3 Classifiers as nominal derivational suffixes 101

5.1.4 Numeral classifiers 103

5.1.5 Verbal classifiers 104

5.1.6 Classifiers with modifiers from closed classes 105

5.2 Functions of classifiers 115

5.3 Repeaters and 'ad hoc' classifiers 117

5.3.1 The use of repeaters 117

5.3.2 The functions of repeaters 118

5.3.3 'Ad hoc' classifiers 119

5.3.4 Classifiers and the lexicon 121

5.4 Summary 121

6. Possession 122

6.1 Personal cross-referencing 122

6.1.1 The system 122

6.1.2 The indefinite prefix 123

6.1.3 Impersonal cross-referencing 126

6.2 Obligatorily possessed nouns 127

6.3 Optionally possessed nouns 128

6.4 Archaisms, innovations and irregularities in obligatorily possessed nouns 129

6.4.1 Archaisms and innovations in marking inalienable possession

6.4.2 Expansion of optionally possessed nouns 129

6.4.3 Retention of possessive suffixes on optionally possessed nouns 131

6.4.4 A common Arawak irregularity in possession marking 133 
Cambridge University Press

978-0-521-02886-8 - A Grammar of Tariana, from Northwest Amazonia

Alexandra Y. Aikhenvald

Frontmatter

More information

6.5 Possessive classifiers 133

6.5.1 Constructions with the possessive $-y a-134$

6.5.2 Constructions with a generic possessed classifier -yarupe 136

6.6 Conclusions 137

7. Case marking and grammatical relations 139

7.1 General properties of case marking system 139

7.2 Semantics and function of core cases 140

7.2.1 The marking of $A, S_{a}, S_{0} 140$

7.2.2 The marking of non- $\mathrm{A} / \mathrm{S}_{\mathrm{a}} / \mathrm{S}_{0} \quad 143$

7.3 The semantics and function of oblique cases 148

7.3.1 Locative case 148

7.3.2 Instrumental-comitative case 150

7.4 Omission of oblique case markers 154

7.5 Marking case more than once 155

7.6 Double case marking and double marking of syntactic function 158

7.6.1 Double case marking 158

7.6.2 Double marking of syntactic function 160

7.7 Summary 163

8. Number 164

8.1 Number marking 164

8.1.1 Inanimate nouns 164

8.1.2 Animate nouns 165

8.1.3 Kinship nouns 166

8.1.4 Uncountable nouns 168

8.1.5 Pluralia tantum 170

8.1.6 Singulatives 171

8.1.7 Associative plural 172

8.2 Plural marking on modifiers 173

8.3 Multiple marking of number 176

8.4 Number agreement 180

8.5 Summary 182

9. Further nominal categories 183

9.1 Tense 183

9.1.1 Nominal future 183

9.1.2 Nominal past 185

9.1.3 Nominal and clausal tense marking: a comparison 187

9.2 Extralocality and restrictivity markers 188

9.3 Contrastive marker 189

9.4 Conjoining morphemes 191

9.5 Approximative 192

9.6 Diminutive and augmentative

9.6.1 Diminutive 193

9.6.2 Augmentative 194

9.7 Pejorative 195 
Cambridge University Press

978-0-521-02886-8 - A Grammar of Tariana, from Northwest Amazonia

Alexandra Y. Aikhenvald

Frontmatter

More information

X Contents

10. Derivation and compounding 196

10.1 Productive derivational suffixes 196

10.2 Semi-productive and non-productive derivational suffixes 197

10.3 Deverbal nominalising affixes 200

10.4 Classifiers and nominal derivation 200

10.5 Compounding 201

11. Closed word classes 203

11.1 Personal pronouns 203

11.2 Specifier articles 204

11.3 Demonstratives 206

11.4 Interrogative-distributive $k w a-/ k w e-208$

11.5 Gestural deictic khi 213

11.6 Distributive individualiser napada 214

11.7 General indefinite $p a:-215$

11.8 Numerals 217

11.9 Quantifiers 219

11.10 Connectives 221

11.11 Adpositions 222

12. Verb classes and predicate structure 234

12.1 Verb classes 234

12.1.1 Ambitransitive, transitive, ditransitive and extended transitive verbs 235

12.1.2 Intransitive verbs 239

12.1.3 Prefixless verbs with two arguments, and extended intransitive verbs 241

12.1.4 Secondary verbs 244

12.1.5 Copula verbs 250

12.2 The structure of a predicate 253

12.3 Verb root structure and verbal derivations 255

12.4 Defining a verbal word 256

13. Valency changing and argument rearranging mechanisms 258

13.1 Passive 258

13.2 Reflexive-reciprocal 263

13.2.1 Reciprocal meanings 263

13.2.2 Reflexive meanings 266

13.3 Increasing transitivity 267

13.3.1 Morphological causatives 267

13.3.2 Causative serial verb constructions 274

13.3.3 Periphrastic causatives 275

13.3.4 Causative mechanisms in Tariana: a comparison 277

13.4 Argument-adding derivation 279

13.5 Argument-manipulating derivation 283

13.6 Summary 286

14. Tense and evidentiality 287

14.1 General remarks 287 
Cambridge University Press

978-0-521-02886-8 - A Grammar of Tariana, from Northwest Amazonia

Alexandra Y. Aikhenvald

Frontmatter

More information

14.2 Tense-evidentiality in affirmative clauses 289

14.2.1 Semantics of tenses 289

14.2.2 Visual evidentials 293

14.2.3 Non-visual evidentials 296

14.2.4 Inferred evidentials 299

14.2.5 Reported evidentials 302

14.2.6 Lexical reinforcement of evidentials 304

14.2.7 Preferred evidentials and their cultural correlates 305

14.2.8 Omission of evidentials and speakers' competence 309

14.3 Tense-evidentiality in interrogative clauses 311

14.3.1 Visual interrogative evidentials 312

14.3.2 Non-visual interrogative evidentials 313

14.3.3 Inferred interrogative evidentials 315

14.3.4 Omission and variability of interrogative evidentials 317

14.3.5 Preferred interrogative evidentials 318

14.4 Future 320

14.5 Final remarks 321

15 Aspect, Aktionsart and degree 324

15.1 Aspect markers 324

15.1.1 'Short duration, little by little' -ina 324

15.1.2 Habitual prescribed -hyuna 326

15.1.3 Customary -kape 328

15.1.4 Habitual repetitive -nipe 329

15.1.5 Anterior -nhi 330

15.1.6 Non-completed ongoing-daka 334

15.1.7 Non-completed ongoing proximate -sida 336

15.1.8 Already accomplished -sita 337

15.1.9 Repetitive -pita, -ta 339

15.1.10 Completive -niki 340

15.1.11 Not quite completed -maña 'just about, almost' 342

15.2 Aktionsart enclitics 342

15.2.1 Aktionsart enclitics with corresponding verbs 343

15.2.2 Aktionsart enclitics not used as independent verbs 348

15.2.3 Semantic and syntactic properties of Aktionsart enclitics

15.3 Degree markers 366

15.4 Emphatic markers 367

16. Mood and modality 371

16.1 Imperatives 371

16.1.1 Unmarked imperative 371

16.1.2 Proximate, distal and postponed imperatives 372

16.1.3 Detrimental imperative 374

16.1.4 Imperative by proxy 376

16.1.5 Conative precative 377

16.1.6 Cohortative 378

16.1.7 Polite suggestion 378

16.1.8 Additional imperatives 379

16.2 Frustrative 380 
Cambridge University Press

978-0-521-02886-8 - A Grammar of Tariana, from Northwest Amazonia

Alexandra Y. Aikhenvald

Frontmatter

More information

xii Contents

16.3 Intentional 383

16.4 Apprehensive 384

16.5 Uncertainty 387

16.6 Conditional 390

16.7 Purposive 393

16.8 Counter-expectation 396

16.9 Declarative-assertive 398

17. Negation 400

17.1 General characteristics of Tariana negation 400

17.2 Clausal negation in non-prohibitive clauses 400

17.3 Negative imperative 409

17.4 Negative prefix ma- 410

17.5 Inherently negative lexemes 411

17.6 Negative ne and negative response 419

17.7 Double negation 421

18. Serial verb constructions and verb compounding 423

18.1 Working definition of a serial verb construction 423

18.2 Defining properties of serial verb constructions in Tariana 424

18.3 Assymmetrical serial verb constructions 430

18.4 Symmetrical serial verb constructions 440

18.5 Ambient serial verb constructions 442

18.6 A comparison of three types of serial verb constructions

443

18.7 Verb compounding 446

19. Complex predicates 449

19.1 Epistemic complex predicate with repetition 449

19.2 Prolonged customary action 450

19.3 Complex predicate with a subordinator and repetition 451

19.4 Passive complex predicate with auxiliary 452

19.5 Apprehensive complex predicate with auxiliary 453

19.6 Admirative complex predicate 453

19.7 Irresultative complex predicate 454

19.8 Complex predicate of small extent 456

19.9 Quasi-serial verb construction 456

19.10 Complex predicates with the optional subordinator $k w e$ and purposive $\operatorname{mood} 457$

19.11 Clause-like complex predicate 457

19.12 Complex predicates and serial verb constructions: a comparison 458

20. Participles and nominalisations 460

20.1 Participles 460

20.2 Nominalisations and converbs 461

20.2.1 The -nipe nominalisation 461

20.2.2 The -mi nominalisation 465

20.2.3 The $-r$ nominalisation 467

20.2.4 Three nominalisations: a comparison 
Cambridge University Press

978-0-521-02886-8 - A Grammar of Tariana, from Northwest Amazonia

Alexandra Y. Aikhenvald

Frontmatter

More information

Contents xiii

20.2.5 Nominalisations and subordinate clauses 472

20.3 Other derivational devices 473

21. Clause types and other syntactic issues 475

21.1 The structure of noun phrases 475

21.1.1 Position of adjectival and closed class modifiers with respect to the head of a noun phrase 475

21.1.2 Discontinuous noun phrases 479

21.1.3 Appositional constructions 480

21.1.4 Headless noun phrases 482

21.1.5 Possessive and adpositional noun phrases 483

21.2 Coordination of noun phrases 484

21.3 Structure of predicates 487

21.4 Types of clauses 487

21.4.1 Declarative clauses 488

21.4.2 Imperative clauses 502

21.4.3 Interrogative clauses 502

21.4.4 Exclamatory clauses 506

21.4.5 Dependent clauses: an overview 506

21.5 Grammatical relations 507

21.5.1 Defining 'subjects' 507

21.5.2 Objects and obliques 511

22. Subordinate clauses and clause linking 515

22.1 Clauses marked with sequencing enclitics 515

22.1.1 Switch reference-sensitive sequencing enclitics 516

22.1.2 Non-switch reference-sensitive sequencing enclitics 525

22.2 Sequential $-k a \quad 528$

22.3 Subordinate clauses marked with adpositions 532

22.4 Subordinate clauses and clause linking 534

23. Relative clauses 537

23.1 Grammatical properties of relative clauses 537

23.2 Content question words as markers of relative clauses

24. Complement clauses 547

24.1 Complement clauses marked with $-k a$ 'subordinator'

24.2 Complement clauses marked with purposive 551

24.3 Complementation strategies 552

24.4 Interrogatives in complement clauses 556

25. Discourse organisation 561

25.1 Pragmatic basis for constituent order 561

25.1.1 Order of words in NPs and multi-word predicates

25.1.2 Pragmatic basis for clausal constituent order 562

25.1.3 Constructions with fixed constituent order 568

25.1.4 'Doubling' of personal pronouns 571

25.2 Ellipsis 573

25.3 Floating enclitics and discourse 574 
Cambridge University Press

978-0-521-02886-8 - A Grammar of Tariana, from Northwest Amazonia

Alexandra Y. Aikhenvald

Frontmatter

More information

xiv Contents

25.4 Repetition and sentence linking devices 576

25.4.1 Repetition 576

25.4.2 Sentence linking strategies 576

25.4.3 Discourse-organising phrase 'I am saying' 583

25.5 Grammatical properties of narratives and conversations

25.5.1 Narratives 585

25.5.2 Conversations 588

25.5.3 Code-switching 590

26. Issues in etymology and semantics 594

26.1 Tariana grammar and lexicon: an etymological perspective 594

26.1.1 Arawak grammar and lexicon in Tariana 594

26.1.2 Semantic restructuring under the influence of East Tucano languages 595

26.1.3 Lexical borrowings 596

26.2 Semantic issues relevant for grammar 598

26.2.1 'Same' and 'different' 599

26.2.2 Generic and specific terms 603

26.2.3 Positional verbs 608

26.3 Remarks on Tariana lexical semantics 616

Appendix. The main features of the Tariana dialects 620

Texts 630

Vocabulary 671

References 682

Index of authors, languages and subjects 690 


\section{Tables, schemes and diagrams}

\section{Tables}

2.1 Consonants 26

2.2 Phonotactic restrictions on the occurrence of consonants 31

2.3 Vowels 32

2.4 Phonotactic restrictions on the occurrence of vowels 33

2.5 Properties of affixes, proclitics and enclitics 42

2.6 Phonetic realisations of independent pronouns 45

3.1 Kinship nouns with fully suppletive vocative forms 69

3.2 Kinship nouns with partly suppletive vocative forms 70

3.3 Kinship nouns which form vocatives by subtraction of the gender sensitive suffix without stress shift 70

3.4 Kinship nouns which form vocatives by stress shift 71

3.5 Kinship nouns which undergo no change in vocatives 71

3.6 Kinship terms which distinguish three forms 71

3.7 Word classes and functional slots in Tariana 81

5.1 Classifiers in Tariana 89

5.2 Classifiers with modifiers of closed classes 114

5.3 Reclassification of a noun: uni 'river, water' 115

6.1 Cross-referencing prefixes and pronouns 122

7.1 Grammatical relations and core cases in Tariana 139

7.2 Oblique cases in Tariana 140

8.1 Personal pronouns in Tariana 177

9.1 Tense in Tariana nouns 183

9.2 Tense in Tariana participles 185

9.3 Properties of the diminutive marker with different word classes 194

10.1 Derivational suffixes 197

10.2 Nominalising affixes 200

11.1 Properties of closed classes 204

11.2 Agreement forms of kwa-/kwe- 209

11.3 Agreement forms of khi- 214

11.4 Agreement forms of napada 214

11.5 Agreement forms of kanapada 221

11.6 Properties of adpositions of the types A-H: a summary 224

12.1 Verbs used as primary and as secondary verbs 248

12.2 Verbs of feeling: a comparison 250

12.3 Prefixless and prefixed copula verbs 251

13.1 Valency reducing mechanisms and verb types 286

14.1 Evidentials and tense in affirmative clauses in Tariana 289

14.2 The semantics of evidentials: a summary 294

14.3 Evidentials and tense in interrogative clauses in Tariana 311

14.4 Evidentials and clause types in Tariana 322 
Cambridge University Press

978-0-521-02886-8 - A Grammar of Tariana, from Northwest Amazonia

Alexandra Y. Aikhenvald

Frontmatter

More information

List of tables, schemes and diagrams

15.1 Aspectual markers in Tariana 325

15.2 Aktionsart enclitics with corresponding verbs 343

15.3 Aktionsart enclitics not used as independent verbs

15.4 Semantics of Aktionsart enclitics 364

17.1 Future and intentional in negative clauses 406

18.1 Verbs which impart aspectual meanings to asymmetrical serial verb constructions 432

18.2 Verbs which impart directional meanings to serial verb constructions 434

18.3 Order of components in assymmetrical serial verb constructions 440

18.4 Asymmetrical, symmetrical and ambient serial verb constructions 444

18.5 Properties of the two types of verb root compounding 448

18.6 Cliticised verb compounding and asymmetrical serial constructions 448

20.1 Nominal and verbal properties of nominalisations 472

22.1 Switch reference-sensitive sequencing enclitics 516

22.2 Properties of subordinate clauses in Tariana 535

23.1 Comparison of main, relative and subordinate clauses 537

25.1 Possible functions of a common NP in two syntactically linked clauses, with some illustrative examples of deletion of its full occurrence 574

26.1 'Sameness' and 'differentness' in Tariana 603

26.2 The uses of -ni 'do' 607

26.3 Semantic features of positional verbs 609

\section{Schemes}

12.1 Predicate structure in Tariana: affixes and roo

12.2 Predicate structure in Tariana: enclitics 254

13.1 Causativising mechanisms, verb types and their semantics

\section{Diagrams}

4.1 Noun structure in Tariana 83

5.1 Semantics and form of articles with classifiers 108

11.1 Semantics and form of demonstratives with classifiers 206

14.1 Preferred evidentials in Tariana 305

14.2 Preferences for evidentials in interrogative clauses 318

14.3 Evidentials in question-response: Tariana and East Tucano 


\section{Preface}

This is a grammar of Tariana, a member of the Arawak family - the largest language family of Central and South America. Tariana was once a dialect continuum spoken by over 1500 people in various settlements along the Vaupés river and its tributaries. The subgroups of Tariana used to constitute a strict hierarchy, and each would speak a different dialect. The difference between individual dialects is comparable to that between Romance languages. As the Catholic missions and white influence expanded, the groups highest up in the hierarchy abandoned Tariana. As the result, the language is actively spoken by only about 100 people, mostly adults, representatives of the lowestranking group Wamiarikune, and is severely endangered. I started assembling data on the language in 1991 and have since worked with most speakers of this dialect of Tariana. As by-products of this work, we produced a bilingual Tariana-Portuguese dictionary, several collections of texts and a practical grammar, and launched a program for teaching Tariana in secondary school. The dedication of the consultants, their insights and their patience made it possible to carry out this daunting task.

This grammar contains an analysis of the Tariana language, starting from a brief characterisation of language and its speakers, then going on to phonology, morphology, syntax, discourse organisation and semantics. The analysis is cast in terms of a cumulative typological framework of linguistic analysis - which employs 'the fundamental theoretical concepts that underlie all work in language description and change' (Dixon 1997: 128) and in terms of which significant typological generalisations are postulated; this has come to be called basic linguistic theory. I have avoided employing any of the more specific formalisms (which come and go with such frequency).

Every chapter of this grammar includes a presentation of the facts of the language interwoven with arguments for their analysis within a typological framework. No attempt has been made to separate pure 'description' from theoretical interpretation. In particular, numerous features of Tariana go against what was thought to be 'universal' for instance, having serial verbs and complex predicates of several distinct types as independent grammatical phenomena, or having gender and classifiers as overlapping means for noun categorisation. A typological perspective for each phenomenon is crucial for the analysis given here.

Tariana is spoken in the multilingual area of the Vaupés basin, characterised by strong cultural inhibition against language mixing - viewed predominantly in terms of loan morphemes. The long-term interaction between East Tucano languages and the Tariana dialect continuum has resulted in a rampant diffusion of patterns and calquing of categories - which include classifiers, tense-evidentiality, number marking and even pronominal cross-referencing. There is a strong areal convergence of patterns - rather than of forms - without, however, implying anything like the emergence of an 'identical' grammar. When appropriate, information on the areally diffused or genetically inherited character of a pattern is included in this grammar. A full analysis of contact-induced developments in Tariana is dealt with in a separate study (Aikhenvald forthcoming-a). 
Detailed exemplification is provided for every grammatical point. Most examples come from texts, and a few from spontaneous - or carefully directed - conversation. An additional objective is to convey as much of the Tariana culture as possible through using naturally occurring examples. I avoid using elicited sentences; elicitation was limited to lexicon and to paradigms.

English glosses are kept as close as possible to the glosses and explanations offered by my consultants. When no English equivalent is readily available, a Portuguese word is used, e.g. abiu-fruit or mucura-rat; some semantically complicated terms are explained in the texts, or in Chapter 1. Readers should be warned against trying to draw conclusions concerning Tariana grammar and semantics from the study of translations.

Examples, tables and diagrams are numbered separately within each chapter. Footnotes are numbered separately for each chapter. The orthography used in the examples from languages other than Tariana, and language names, follows that of the sources (unless indicated otherwise).

This grammar can be used as a sourcebook for further typological studies, and as a model for further grammars of languages of Arawak and of other families of the Americas. It is far from being the last word on Tariana - this grammar is intended to provide a sound systematic foundation for further studies, reanalyses and reinterpretations.

It is my hope that this book will encourage linguists to go out into the field and document languages threatened by extinction (before it is too late to do so), notwithstanding the difficulties and temporary frustrations which necessarily accompany a fieldworker. 


\section{Acknowledgements}

My warmest thanks go to the Brito family who taught me their language and accepted me as a member of their family. When in July 1991 Graciliano Sanchez Brito ('Gara') appeared in a makeshift house in the township of São Gabriel da Cachoeira (state of Amazonas, Brazil) that I was sharing with a few students from the Federal University of Santa Catarina, little could I suspect that he would become my main teacher, and then my classificatory older brother. Later I met his brothers, Jovino and José Luiz, his sister Olívia, and his parents. His father, Cândido Brito - one of the few traditional speakers and a real treasure-chest of Tariana lore and culture - was an indefatigable and patient teacher. And his mother, Maria Sanchez - a Piratapuya herself - adopted me as her daughter and taught me quite a few secrets about the life of Vaupés women. Gara's cousin, Rafael, the youngest speaker of the Santa Rosa dialect, has always been extraordinarily helpful, besides being great fun to have around.

When I went to the villages of Iauaretê and Santa Rosa, I met Ismael (Mayẽ) Brito, Gara's older brother, and Leonardo Brito, Cândido's younger brother. I learnt an enormous amount from both of them.

It is hard to find words to express my gratitude to these people.

I learnt a lot from all the other speakers of the Tariana dialect of Santa Rosa - who told me stories, or came to chat - Ricardo Brito (Diká) and his sons Emílio and Raimundo; José Manoel Brito and his children Sebastião (Saba), Cristiano (Kiri), João $(\tilde{N} u)$, Clementina and Joaninha; Juvenal, Abelardo and their mother Amélia (a Guanano herself); Cristina, married to Abelardo; Jacinto Brito, and Batista Brito. Américo Brito, the oldest living speaker of Tariana, shared with me his eyewitness accounts of the offering feasts - he is the only living Tariana to have seen them.

The women in Santa Rosa made an effort to communicate with me and help me in many ways. Some spoke Tariana, like Cecília (Leonardo's wife). With others, our language of communication was rudimentary Tucano and Portuguese. I am deeply grateful to Edna Lúcia, Maria do Carmo, Clemência, Marília, Silvana and Maurília. Feli Brito (Batista's son) knew no Tariana - I am grateful to him simply for being kind. And there are so many more people to thank - Eduardo Brito and his wife Antônia; Júlia Brito and Nestor Brito - for their hospitality and friendship

My warmest gratitude also goes to the people of Periquitos, for teaching me their variety of Tariana, and for their perseverance in maintaining the language and speaking it to their children. I am grateful to the elders: Marino and Jorge Muniz; to the younger generation: Domingo, Ismael, Batista, Dário, Vivaldo, Gustavo and João Bosco; and to the women of Periquitos - Alice, Maria Carlota, Ester Belinda and others - who are quietly determined to save Tariana. The future of the language is in their hands!

I met Roni Lopez, a speaker of the Santa Terezinha dialect, just once. I am deeply grateful to him for his patience and interest in teaching me his dialect.

I would also like to acknowledge my debt to Padre Casimiro Bekšta, an expert on the area of the Upper Rio Negro and the Vaupés, who frequently helped with information and advice. He was the first person to mention to me, back in 1990, that Tariana is still 
spoken by a very remote group, upstream from Iauaretê. And he has, ever since, been a real encyclopedia of the Upper Rio Negro region for me. I have also profited from discussions with Elias Coelho, Janet Barnes, Henri Ramirez and Stephen Hugh-Jones.

I am grateful to all my ex-students and friends from Brazil, who accompanied me at the initial stages of fieldwork and provided me their friendship and support - Simoni Valadares, Tatiana Santos, Marcos Baltar, Antônio Augusto de Souza Melo, Cristiane Cunha de Oliveira and especially Rute Maria Coelho.

This grammar would have been impossible without the assistance, support and friendship of Silvana and Valteir Martins. Lenita and Elias Coelho provided me with a second home in São Gabriel da Cachoeira, looking after me, and giving me advice in every aspect of life, and concerning fieldwork in the remote areas of the Upper Rio Negro.

My gratitude goes to all those people from the Upper Rio Negro area who taught me their languages: Humberto Baltazar and Pedro Ângelo Tomas (Warekena); the late Candelário da Silva (Bare); Afonso, Albino and João Fontes, Celestino da Silva, Cecília and Laureano da Silva and the late Marcília Rodrigues (Baniwa); the late Tiago Cardoso (Desano, Piratapuya), and also Alfredo Fontes (Tucano).

Warmest thanks go to Sisters Aline Sienkiewicz, Dária Moratelli, Cristina, Rita and Ireni - who looked after me in so many different ways, making their mission welcome for me - during my stays in lauaretê.

All those who participated in the Tariana literacy class and helped organise it deserve separate thanks. Marta Azevedo provided us with the infrastructure and food; she also organised a Pedagogical workshop which resulted in the creation of quite a number of stories in Tariana. And without Glória da Silva, Cecília da Silva, Lourdes Brito, Galdino Pinheiro, Pedro Jesús, Padre Jesus, Padre Benjamim, Sister Dária Moratelli, Jaqueline Brito, Vanilde Brito, Nestor Brito and many, many others, this course would not have happened.

I am most grateful to those who read through the whole draft of this book, or parts of it, and provided comments, corrections and ideas - Willem Adelaar, Avery Andrews, Timothy J. Curnow, Antoine Guillaume, Keren Rice, Tom Payne, Gunter Senft, Fritz Serzisko and Mary Ruth Wise. Invaluable comments on almost every page came from R. M. W. Dixon, without whose constant encouragement and support I would have never completed this grammar.

Tonya Stebbins and Carol El-Chaar carefully read through the draft of this book and corrected it. Adam Bowles formatted the volume with meticulous care. Thanks are equally due to them. Siew Peng Condon provided a wonderful working atmosphere at the Research Centre for Linguistic Typology. This book would have been scarcely possible without her.

I gratefully acknowledge the Wenner Gren Foundation for a grant which made my fieldwork financially feasible. 


\section{Organisation and cross-referencing}

A brief overview of the linguistic profile of Tariana is found at the beginning of Chapter 1. Phonology is discussed in Chapter 2. Chapter 3 contains an outline of word classes. Chapters 4-20 deal with various aspects of morphology, while syntactic issues are considered in Chapters 21-24. Chapter 25 deals with discourse organisation, and Chapter 26 provides a brief sketch of semantic issues, especially those relevant to the understanding of the grammar.

Here and passim '-' stands for any morpheme boundary, that is, a boundary between a root and an affix, or between two roots. The symbol $1=$ ' indicates a boundary between a root and a clitic, or an affix and a clitic, or two clitics (see Chapter 2). The symbol ' indicates a primary stress, and "indicates a secondary stress (obligatory on enclitics). Stress is marked on each example in Chapter 2 ('Phonology') and in other chapters only if it is relevant to the discussion. Since nasal vowels and long vowels are always stressed, stress on these is not marked.

In Tariana there is a considerable amount of variation between certain allophones (discussed in Chapter 2). Examples of alternative pronunciations are yápi, ñápi 'bone', yápu, ñápu 'stream', yama, ñama 'two', pamúya, pamúña 'middle', -pidena, -pidana 'remote past reported', -naku, -nuku 'topical non-subject', -nuka, -naka 'present visual', di-keña, di-keñwa 'he begins'. There is also variation between long vowels and short vowels, e.g. ke:ri, keri 'moon', na:, na 'they went, they said'. Most of these variants depend on the age and proficiency of the speaker; every example in this grammar records the actual pronunciation by the consultant.

Examples are numbered separately for each chapter. All the examples and texts are supplied with an interlinear morpheme gloss, and then translated into English. Homophonous morphemes (e.g. -nha 'pausal marker; interrogative present visual; imperative (containing doubt)') are differentiated by their glosses. The symbol ' + ' is used to indicate fused morphemes, e.g. direta 'he ordered' is glossed as 3 sgnf + order+CAUS, its underlying form being di- (3sgnf) -ira (order) -ita (CAUS). Portmanteau morphemes are glossed with a ':', for instance, -peni (PL:ANIM) 'plural.animate'. All grammatical morphemes are glossed in small caps while lexical morphemes are glossed in lower case. Pronominal prefixes are shown as $1 \mathrm{sg}, 3 \mathrm{pl}$, in lower case. For polysemous morphemes, different translation in glosses corresponds to different meanings; for instance - $k a k a$ 'reflexive-reciprocal' is glossed as REFL when it has reflexive meaning and as $\mathrm{RC}$ when it has reciprocal meaning.

Cross-references are of two kinds:

- those preceded by $\S$ refer to chapter and section number, e.g. $\S 11.1$ refers to section 1 of Chapter 11;

- those beginning with a number refer to examples in the grammar, e.g. 11.1 refers to example 1 in Chapter 11. 
Cambridge University Press

978-0-521-02886-8 - A Grammar of Tariana, from Northwest Amazonia

Alexandra Y. Aikhenvald

Frontmatter

More information

xxii

\section{Abbreviations}

A

ABSTR

ACT.CONTR

ADM

ADV

AFF

ANIM

ANT

APPR

APPROX

ART

ASS.PL

AUG

AUX

CAUS

$\mathrm{CL}$

COHORT

COLL

COM

COMPL

COND

CONV

CONTR

CONTR.ACT

COUNTEREX

CURV

CUST

DECL

DEM

DIM

DIST

DISTRIB

DS

EMPH

EX(IST)

EXC

EXTRAL

f, fem, FEM

FOC.A/S

FR

FUT transitive subject

abstract

action contrast

admirative

adverbial

derivational affix

animate

anterior

apprehensive

approximative

article

associative plural

augmentative

auxiliary

causative

classifier

cohortative

collective

comitative

completive

conditional

converb

contrastive

contrast of actions

counter-expectation

curved

customary

declarative

demonstrative

diminutive

distal

distibutive plural

different subject

emphatic

existential

excessive

extralocal

feminine

focussed subject

frustrative

future
FUT.CERT

FUT.UNCERT

GEN

GEN.INFR

$\mathrm{HAB}$

HABIT

HORT

HUM

IMP

IMPV

IMPV.DETR

IMP.SEC

INAN

INDF

INFR

INS

INT

INTER

IRRES

LOC

LOCN

MASC

NAT.PHEN

NCL

NEG

NEG.EX

$\mathrm{NF}, \mathrm{nf}$

NOM

NOM.FUT

NOM.PAST

NONVIS

NPOSS

NON.INDIV

$\mathrm{O}$

OBJ

NUM.CL

$\mathrm{p}$

P.REL

PART certain future

uncertain future

generic

generic inferred

habitat

habitual

hortative

human

impersonal

imperative

detrimental

imperative

secondhand

imperative

inanimate

indefinite

inferred

instrumental

intentional

interrogative

irresultative

locative

locational

masculine

natural phenomena

noun class

negative

negative existential

non-feminine

nominalising

nominal future

nominal past

non-visual

non-possessed

non-individuated

object

objective case

numeral classifier

person

past relative

participle 
Cambridge University Press

978-0-521-02886-8 - A Grammar of Tariana, from Northwest Amazonia

Alexandra Y. Aikhenvald

Frontmatter

More information

List of abbreviations xxiii

\begin{tabular}{|c|c|c|c|}
\hline PART.CONTR & participant contrast & REP & reported \\
\hline PASS & passive & REPET & repetitive \\
\hline PAUS & pausal & $\mathrm{S}$ & subject of an \\
\hline PEJ & pejorative & & intransitive verb \\
\hline PERF & perfective & $\mathrm{S}_{\mathrm{a}}$ & subject of an active \\
\hline PL, pl & plural & & intransitive verb \\
\hline POL.SUG & polite suggestion & $S_{i o}$ & subject of an \\
\hline POSS & possessive & & intransitive verb with \\
\hline POSTP.IMPV & postponed imperative & & a non-canonically \\
\hline POT & potential & & marked argument \\
\hline PREC & precative & $S_{o}$ & subject of a stative \\
\hline PRES & present & & intransitive verb \\
\hline PROH & prohibitive & SPEC.INFR & specific inferred \\
\hline PROX & proximate & SUB & subordinating \\
\hline PURP.NONVIS & purposive non-visual & $\mathrm{SG}, \mathrm{sg}$ & singular \\
\hline PURP.VIS & purposive visual & SINGL & singulative \\
\hline QUAL & qualificative & SS & same subject \\
\hline REC & reciprocal & $\mathrm{TH}$ & thematic \\
\hline REC.P & recent past & TOP.ADV & topic-advancing voice \\
\hline REF & referential kinship & TOP.NON.A/S & topical non \\
\hline & term & UNCERT & uncertainty-subject \\
\hline REFL & reflexive & VERT & vertical \\
\hline REL & relative & VIS & visual \\
\hline REM.P & remote past & VOC & vocative \\
\hline
\end{tabular}




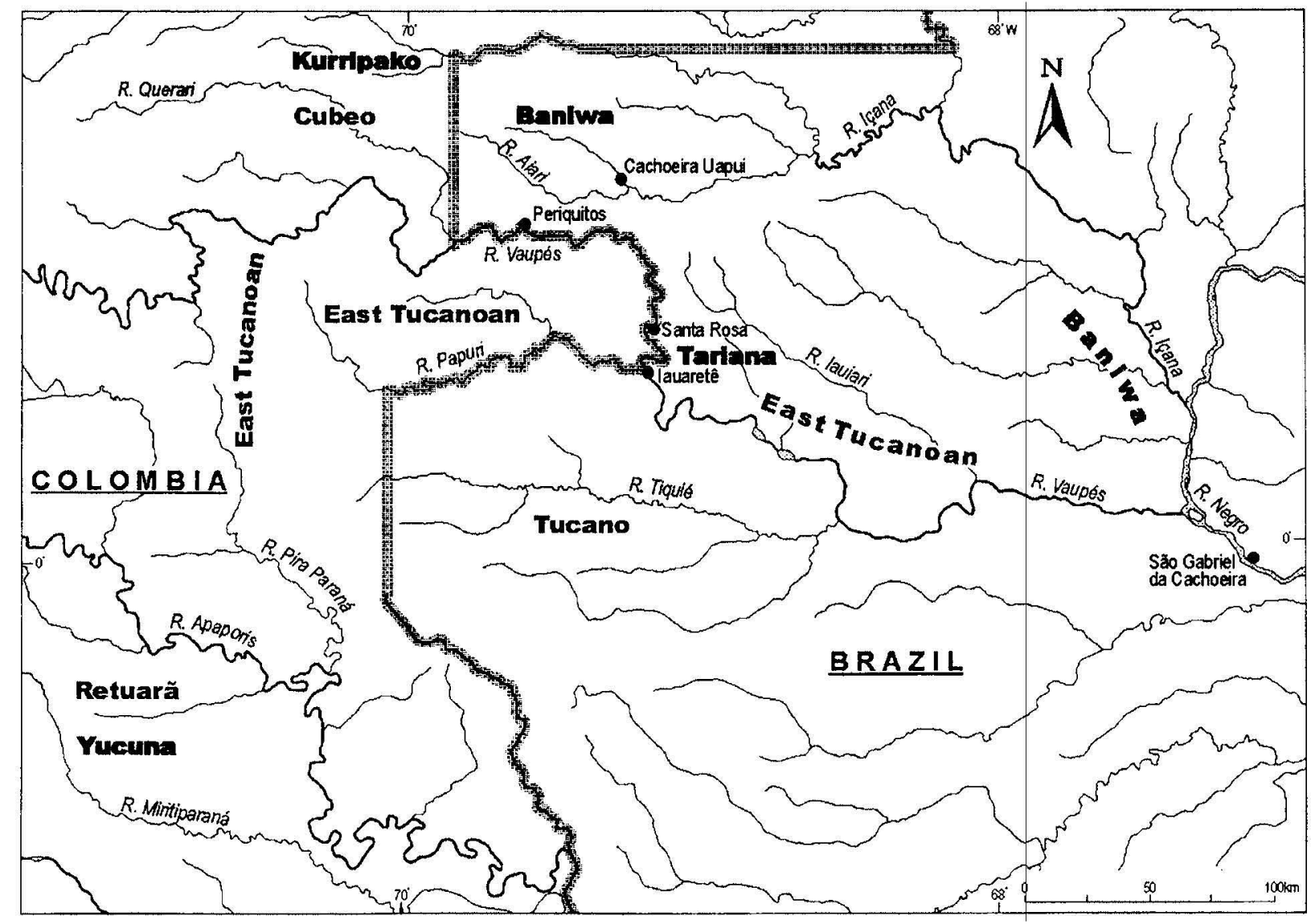

MAP. ARA WAK AND TUCANOAN LANGUAGES IN NORTH-WESTERN AMAZONIA 